\title{
Modelling the transport phenomena and texture changes of chicken breast meat during the roasting in a convective oven
}

\author{
Rabeler, Felix; Feyissa, Aberham Hailu
}

Published in:

Journal of Food Engineering

Link to article, DOI:

10.1016/j.jfoodeng.2018.05.021

Publication date:

2018

Document Version

Peer reviewed version

Link back to DTU Orbit

Citation (APA):

Rabeler, F., \& Feyissa, A. H. (2018). Modelling the transport phenomena and texture changes of chicken breast meat during the roasting in a convective oven. Journal of Food Engineering, 237, 60-68.

https://doi.org/10.1016/j.jfoodeng.2018.05.021

\section{General rights}

Copyright and moral rights for the publications made accessible in the public portal are retained by the authors and/or other copyright owners and it is a condition of accessing publications that users recognise and abide by the legal requirements associated with these rights.

- Users may download and print one copy of any publication from the public portal for the purpose of private study or research.

- You may not further distribute the material or use it for any profit-making activity or commercial gain

- You may freely distribute the URL identifying the publication in the public portal

If you believe that this document breaches copyright please contact us providing details, and we will remove access to the work immediately and investigate your claim 
1 Modelling the transport phenomena and texture changes of chicken breast meat during the

2 roasting in a convective oven

3

4 Felix Rabeler, Aberham Hailu Feyissa*

5 Food Production Engineering, National Food Institute, Technical University of Denmark (DTU),

6 Denmark

$7 \quad{ }^{*}$ Corresponding author:

8 Søltofts Plads, 2800, Kgs. Lyngby, Denmark

$9 \quad$ Email address: abhfe@food.dtu.dk, Tel.: +45 45252531

12 Keywords: COMSOL Multiphysics, heat and mass transfer, poultry meat, quality prediction,

13 thermal processing, transport in porous media

15 Abstract

16 A numerical 3D model of coupled transport phenomena and texture changes during the roasting

17 of chicken breast meat in a convection oven was developed. The model is based on heat and mass

18 transfer coupled with the kinetics of temperature induced texture changes of chicken breast meat.

19 The partial differential equations of heat and mass transfer as well as the ordinary differential

20 equations that describe the kinetics of the texture changes were solved using COMSOL

21 Multiphysics ${ }^{\circledR}$ 5.2a. The predicted temperature, moisture and texture (hardness, chewiness and

22 gumminess) profiles were validated using experimentally values. The developed model enables

23 the prediction of the texture development inside the chicken meat as function of the process 
24 parameters. The model predictions and measured values show the clear effect of changing

25 process settings on the texture profiles during the roasting process. Overall, the developed model

26 provides deep insights into the local and spatial texture changes of chicken breast meat during the

27 roasting process that cannot be gained by experimentation alone.

\section{1. Introduction}

29 Heat treatment of chicken breast meat is a crucial processing step in households, professional

30 kitchens and large-scale food industries to achieve a safe and high quality product. Roasting of

31 chicken meat in a convection oven is a common process that involves simultaneous heat and

32 mass transfer. However, the roasting affects the microstructure (Feyissa et al., 2013;

33 Wattanachant et al., 2005), texture (Wattanachant et al., 2005) and appearance (Fletcher et al.,

34 2000) of the product and, consequently, its acceptance by the consumer.

35 The texture of the chicken meat is the highest rated quality attribute for the consumer during

36 consumption (Lawrie and Ledward, 2006) and it is mainly influenced by protein denaturation

37 which leads to fiber shrinkage and straightening (Tornberg, 2005; Wattanachant et al., 2005).

38 Consequently, the microstructure is becoming denser with compact fiber arrangements which

39 results in the toughening of the chicken meat during the heating (Christensen et al., 2000; Lewis

40 and Purslow, 1989; Wattanachant et al., 2005). Moreover, the protein denaturation leads to a

41 reduction of the water holding capacity (WHC) of the chicken breast meat. The unbound water

42 migrates into the spaces between the meat fibers which leads to a toughening of the meat and to

43 the loss of water during the roasting process (Micklander et al., 2002; Tornberg, 2005).

44 The quality of the final product is mainly controlled by the chef or operator through adjustments

45 of the process settings. However, this is still based on the cook-and-look approach, which relies

46 on the experience and skills of the chef or operator. A number of researchers measured 
47 experimentally the texture change of poultry meat with temperature (Barbanti and Pasquini,

48 2005; Wattanachant et al., 2005; Zell et al., 2010) and Rabeler and Feyissa (2017, submitted for

49 publication) developed kinetic models to describe these changes with time. However, to gain the

50 relationship between the process conditions and the texture development inside the chicken meat,

51 the spatial temperature and time history during the roasting process is needed.

52 Mechanistic models of heat and mass transfer (based on fundamental physical laws) are able to

53 predict the temperature and moisture distribution during the cooking process of meat (Feyissa et

54 al., 2013; van der Sman, 2007), beef meat (Kondjoyan et al., 2013; Obuz et al., 2002) or poultry

55 meat (Chang et al., 1998; van der Sman, 2013). However, for the roasting of chicken breast meat

56 only a limited number of mathematical models are available.

57 Chen et al. (1999) developed a model of heat and mass transfer for convection cooking of

58 chicken patties. In their model they described the transport of moisture inside the chicken patties

59 by diffusion, which is a common approach for modelling mass transfer (Huang and Mittal, 1995;

60 Isleroglu and Kaymak-Ertekin, 2016; Kassama et al., 2014). However, the moisture transport

61 during the cooking process cannot be explained adequately by pure diffusion models (Feyissa et

62 al., 2013; van der Sman, 2007). Roasting of chicken breast meat leads to protein denaturation, the

63 shrinkage of the protein network and the reduction of the water holding capacity. This induces a

64 pressure gradient inside the meat and the expulsion of the excess moisture to the surface of the

65 meat.

66 This approach was used by van der Sman (2013) to model the cooking of chicken breast meat in

67 an industrial tunnel oven. The author showed that the model is able to predict the temperature and

68 moisture development inside the chicken meat for cooking temperatures below the boiling point.

69 However, the presented cooking temperatures (45 to $100^{\circ} \mathrm{C}$ ) and times (up to $160 \mathrm{~min}$ ) are not 
70 common settings for the roasting of chicken meat in industrial convection ovens, where hot dry

71 air with more than $150{ }^{\circ} \mathrm{C}$ is employed (Chen et al., 1999; Guerrero-Legarreta and Hui, 2010).

72 Thussu and Datta (2012) showed that by coupling texture kinetics with physical based models of

73 heat and mass transfer, the texture development during the frying of potato stripes can be

74 predicted. However, for chicken breast meat or other muscle foods no attempt was made to

75 couple kinetic models for textural changes with mechanistic models of heat and mass transfer to

76 predict the local and spatial texture changes.

77 Therefore, the aim of this study is to first develop a mechanistic model to predict the temperature

78 and moisture profiles of chicken breast meat during the roasting in a convection oven. Our

79 hypothesis is then that by coupling the developed model for heat and mass transfer with the

80 kinetic models of heat induced textural changes for chicken meat, the texture profile during the

81 roasting process can be predicted as function of process parameters. Afterwards, the model

82 predictions will be validated against experimental values.

\section{2. Modelling of transport phenomena and texture changes}

\section{$84 \quad$ 2.1. Process description and model formulation}

85 Roasting in a convection oven is a thermal process, where the product is heated at high

86 temperatures $\left(150-300^{\circ} \mathrm{C}\right)$ by circulated hot air. The main mechanisms during the roasting of

87 chicken breast meat in a convective oven are illustrated in Fig. 1. Heat is transferred mainly

88 through convection from the surrounding circulated hot air while a conductive heat flux comes

89 from the roasting tray (bottom of chicken breast). The surrounding oven walls are made of

90 polished stainless steel, thus, the effect of radiation is small compared to the convective transport

91 (see section 3.2.1) (Feyissa et al., 2013). The effect of radiation was included in the model by

92 using an estimated effective heat transfer coefficient (combined convective and radiative heat 
93 transfer coefficient, see section 3.2.1) (Kondjoyan and Portanguen, 2008; Sakin-Yilmazer et al., 94 2012; Zhang and Datta, 2006). The heat is then internally transferred by conduction and 95 convection.

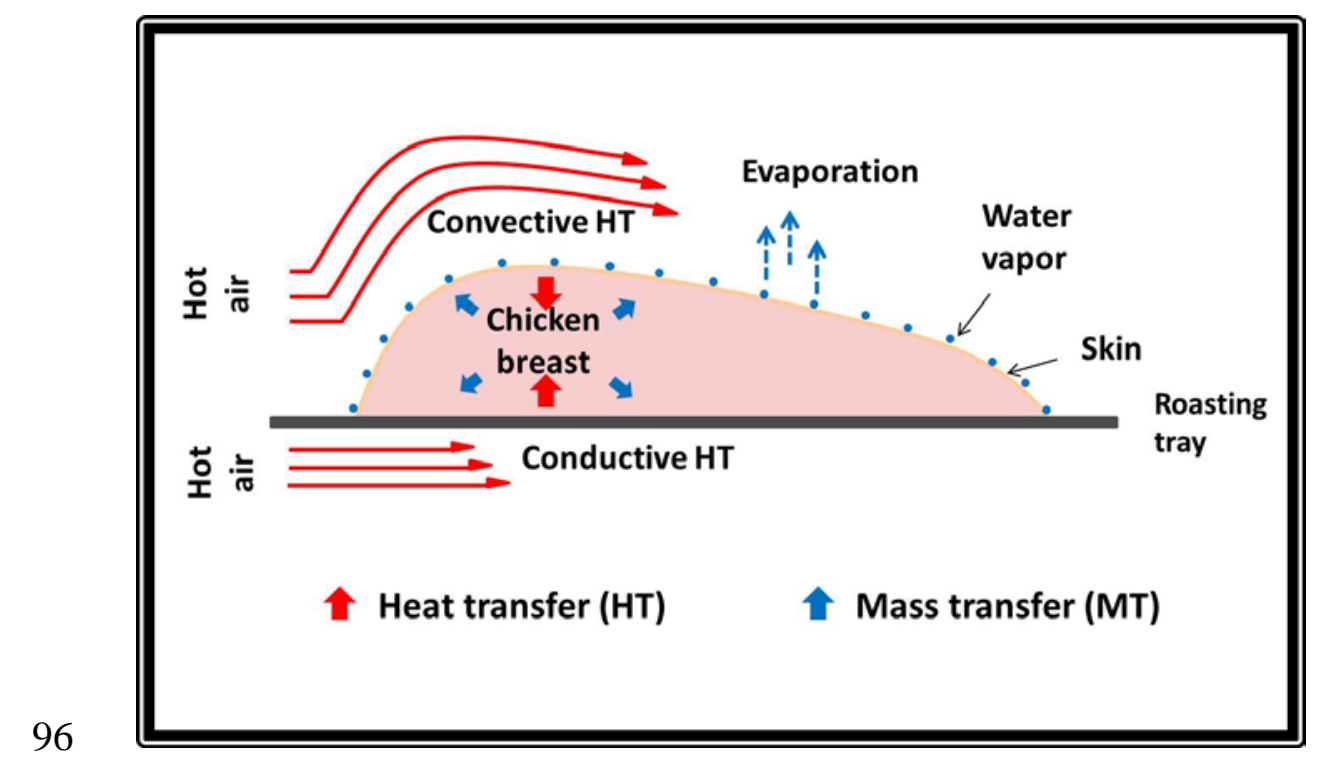

97 Fig. 1. Schematic illustration of the main mechanisms during the roasting of chicken breast meat in a convection oven.

99 Water migration within the product takes place by diffusion and convection mechanisms. The

100 latter is a result of the heat induced protein denaturation and shrinkage of the protein network,

101 which results in the decrease of the water holding capacity and a pressure gradient inside the

102 chicken meat. This so called swelling pressure is the driving force for the convective water

103 transport inside the meat and can be described by Darcy's law for flow through porous media

104 (van der Sman, 2007). Liquid water that is expelled to the product surface is then evaporated to

105 the surrounding hot air.

106 From the measured temperature profiles inside the chicken meat we observed that the

107 temperature stays below the evaporation temperature and only a thin crust is formed during the

108 roasting. Thus, internal evaporation of water was neglected in this study. Furthermore, the

109 following basic assumptions are made to formulate the governing equations for the coupled heat 
110 and mass transfer: fat transport inside the chicken meat is negligible (since the fat content is less

111 than $1 \%$ in chicken breast meat), evaporated water consists of pure water (no dissolved matter,

112 measured similar to Feyissa et al. (2013)) and no internal heat generation.

\section{2.2. Governing equations}

\section{$114 \quad$ 2.2.1. Heat transfer}

115 The heat transfer within the chicken breast meat is given by Eq. (1) (Bird et al., 2007)

$116 c_{p, c m} \rho_{c m} \frac{\partial T}{\partial t}=\nabla\left(k_{c m} \nabla T\right)-\rho_{w} c_{p, w} u_{w} \nabla T$

117 where $c_{p, c m}$ and $c_{p, w}$ are the specific heat capacities of chicken meat and water $(\mathrm{J} /(\mathrm{kg} \mathrm{K}))$,

118 respectively, $\rho_{c m}$ and $\rho_{w}$ are the densities of chicken meat and water $\left(\mathrm{kg} / \mathrm{m}^{3}\right)$, respectively, $k_{c m}$ is

119 the thermal conductivity of chicken breast meat (W/(m K)), $u_{w}$ the velocity of the fluid $(\mathrm{m} / \mathrm{s}), T$ is

120 the temperature (K) and $t$ is the time (s).

\section{$121 \quad$ 2.2.2. Mass transfer}

122 The governing equation for water transport is based on the conservation of mass and is given by

123 Eq. (2) (Bird et al., 2007)

$124 \frac{\partial C}{\partial t}=\nabla\left(-D \nabla C+C u_{w}\right)$

125 where $C$ is the moisture concentration ( $\mathrm{kg}$ of water $/ \mathrm{kg}$ of sample) and $D$ is the moisture diffusion

126 coefficient $\left(\mathrm{m}^{2} / \mathrm{s}\right)$.

127 Darcy's law gives the relationship between moisture transport and pressure gradient inside a

128 porous medium (in this case meat) and the velocity of the fluid inside the chicken meat can be

129 expressed as

$130 \quad u_{w}=\frac{-\kappa}{\mu_{w}} \nabla p$ 
131 where $\kappa$ is the permeability of the chicken meat $\left(\mathrm{m}^{2}\right), \mu_{w}$ is the dynamic viscosity of the fluid (Pa

132 s) and $\nabla p$ is the pressure gradient vector $(\mathrm{Pa} / \mathrm{m})$. The swelling pressure is given by Eq. (4)

133 (Barrière and Leibler, 2003; van der Sman, 2007)

$134 p=G^{\prime}\left(C-C_{e q}\right)$

135 with $G$ ' the storage modulus and $C_{e q}$ the water holding capacity of chicken breast meat.

136 By inserting the expression for the swelling pressure (Eq. (4)) into Eq. (3) the following

137 expression results for the fluid velocity $u_{w}$ :

$138 u_{w}=\frac{-\kappa G \prime}{\mu_{w}} \nabla\left(\mathrm{C}-C_{e q}\right)$

139 The storage modulus varies with temperature and was described by with a sigmoidal function

140 (Eq. (6)) (Rabeler and Feyissa, 2017, submitted for publication):

$141 G^{\prime}=G_{\text {max }}^{\prime}+\frac{\left(G^{\prime}-G^{\prime} \max \right)}{1+\exp \left(\frac{T-\bar{T}}{\Delta T}\right)}$

142 with $G^{\prime}{ }_{\max }=92 \mathrm{kPa}$ (the maximum value of the storage modulus for chicken meat), $G^{\prime}{ }_{0}=13.5$

$143 \mathrm{kPa}$ (the initial value of the storage modulus), $\bar{T}=69^{\circ} \mathrm{C}$ and $\Delta T=4^{\circ} \mathrm{C}$.

144 The change in the water holding capacity with temperature is described by Eq. (7) (van der Sman, 145 2013):

$146 C_{e q(T)}=y_{w 0}-\frac{a_{1}}{1+a_{2} \exp \left(-a_{3}\left(T-T_{\sigma}\right)\right)}$

147 where $\mathrm{y}_{\mathrm{w} 0}=0.77$ is the initial water content of raw chicken meat, $T_{\sigma}=315 \mathrm{~K}, a_{1}=0.31, a_{2}=30.0$

$148 \quad$ and $\mathrm{a}_{3}=0.17$.

$149 \quad$ 2.3. Initial and boundary conditions

150 We assume a uniform initial temperature (Eq. (8)) and moisture distribution (Eq. (9)) throughout 151 the whole sample domain (Fig. 2b):

$152 T(x, y, z, 0)=T_{0}$ 
a)

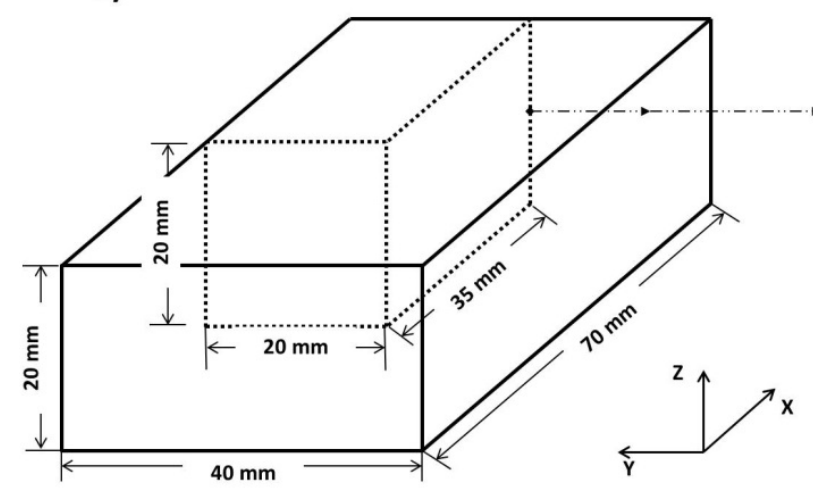

b)

b)

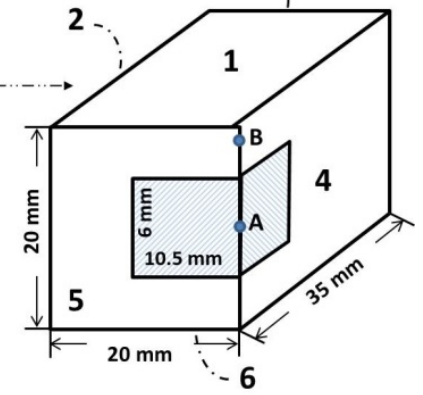

Fig. 2. Schematic illustration of (a) the rectangular chicken meat sample and (b) the geometry used in the developed model. The points: A $(0,0,10 \mathrm{~mm})$ and $B(0,0,19 \mathrm{~mm})$ indicate the position of the two thermocouples and the striped part shows the domain for the texture validation.

\subsubsection{Heat transfer boundary condition}

160 The boundaries 1, 2 and 3 (see Fig. 2) are exposed to the hot air and the heat flux is given by Eq.

161 (10):

162

$-k_{c m} \nabla T=h_{e f f}\left(T_{\text {oven }}-T_{\text {surf }}\right)$

163 where $k_{c m}$ is the thermal conductivity of the chicken breast meat (W/(m K)), $h_{\text {eff }}$ is the effective

164 heat transfer coefficient $\left(\mathrm{W} /\left(\mathrm{m}^{2} \mathrm{~K}\right)\right)$, which is the sum of both the convective and radiative heat

165 transfer (Sakin et al., 2009) (see section 3.2.1), $T_{\text {oven }}$ is the oven temperature $(\mathrm{K})$ and $T_{\text {surf }}$ is the

166 surface temperature (K) of the chicken breast meat.

167 At boundary 6 the chicken meat is in contact with the roasting plate and a heat flux at this

168 boundary is given by Eq. (11):

$-k_{c m} \nabla T=h_{b o t}\left(T_{\text {oven }}-T_{b o t}\right)$

170 with the heat transfer coefficient $h_{b o t}$ and bottom surface temperature $T_{\text {bot }}\left(\mathrm{W} /\left(\mathrm{m}^{2} \mathrm{~K}\right)\right)$.

171 Boundaries 5 and 4 are symmetry boundary conditions. 


\section{$172 \quad$ 2.3.2. Mass transfer boundary condition}

173 The water evaporation at the boundaries 1, 2, 3 and 6 is given by Eq. (12):

$174-D \nabla C+C u_{w}=\beta_{\text {tot }}\left(C_{\text {surf }}-C_{\text {oven }}\right)^{\mathfrak{a}}$

175 where $\beta_{\text {tot }}$ is the mass transfer coefficient $(\mathrm{m} / \mathrm{s}), C_{\text {surf }}$ is the water vapor concentration at the

176 surface of the meat $(\mathrm{kg} / \mathrm{kg})$ and $C_{\text {oven }}$ the water vapor concentration in the air flow inside the

177 oven.

178 Van der Sman (2013) reported that the top layer (epimysium connective tissue) of the chicken

179 breast meat becomes glassy during the roasting which results in an increased resistance against

180 water evaporation. To take this into account the author formulated a mass transfer coefficient $\beta_{\text {skin }}$

181 (Eq. 13)) which is dependent on the local moisture content at the surface of the chicken breast

182 meat.

$183 \beta_{\text {skin }}=\beta_{1} y_{w}{ }^{b}$

184 where $\beta_{1}$ and $b$ are 0.040 [m/s] and 4.0 , respectively (van der Sman, 2013).

185 The total mass transfer coefficient is then given by Eq. (14):

$186 \frac{1}{\beta_{\text {tot }}}=\frac{1}{\beta_{\text {ext }}}+\frac{1}{\beta_{\text {skin }}}$

187 where $\beta_{\text {ext }}$ refers to the external mass transfer coefficient which is calculated using the Lewis

188 relation (Eq. (15)):

$189 \quad \beta_{\text {ext }}=\frac{h}{\rho_{a} c_{p, a} L e^{2 / 3}}$

190 Boundaries 5 and 4 are symmetry boundary conditions.

\section{$191 \quad$ 2.4. Thermo-physical properties}

192 The thermo-physical properties of chicken breast meat were described as function of composition

193 and temperature (including the effect of fiber direction) (Choi and Okos, 1986). For the thermal

194 conductivity we assume that all fibers are oriented along the x-axis (see Fig. 2) of the chicken 
195 breast. The thermal conductivity parallel to the fibers $\left(\mathrm{k}_{\mathrm{cm}, \|}\right)$ is calculated using the parallel

196 model (Eq. (16)) and for the thermal conductivity perpendicular to the fibers $\left(\mathrm{k}_{\mathrm{cm}, \perp}\right)$, we assume

197 the serial model (Eq. (17)).

$198 k_{c m, \|}=\sum k_{i} \phi_{i}$

$199 \frac{1}{k_{c m, \perp}}=\sum \frac{\phi_{i}}{k_{i}}$

200 where $k_{i}$ and $\phi_{i}$ are the thermal conductivities $(\mathrm{W} /(\mathrm{m} \mathrm{K}))$ and volume fractions of the each

201 component i (water, protein, fat and ash), respectively.

202 The specific heat capacity $(\mathrm{J} /(\mathrm{kg} \mathrm{K}))$ of chicken meat is calculated using Eq. (18)

$203 \quad c_{p, c m}=\sum y_{i} c_{p, i}$

204 where $y_{i}$ and $c_{p, i}$ are the mass fraction and specific heat capacity of each component i (water,

205 protein, fat and ash), respectively.

\section{$206 \quad$ 2.5. Kinetic model for texture changes}

207 A modified reaction rate law, which is taking into account that foods retain a non-zero

208 equilibrium even after long heating times, was used to describe the texture (hardness, gumminess

209 and chewiness) changes of chicken breast meat with temperature and time (for details see

210 (Rabeler and Feyissa, 2017, submitted for publication)) (Eq. 19):

$211 \frac{\partial Q}{\partial t}=k\left(Q_{\infty}-Q\right)^{n}$

212 where $Q$ is the quality attribute, $Q_{\infty}$ is the final non-zero equilibrium quality value after long

213 heating times, $k$ is the reaction rate constant $\left(\min ^{-1}[\mathrm{Q}]^{1-n}\right)$ and $n$ the reaction order.

214 The temperature dependence of the reaction rate constant is described by the Arrhenius equation

215 as followed (Eq. (20)):

$216 k=k_{0} e^{-\frac{E a}{R T}}$ 
217 with $k_{0}$ the pre-exponential factor $\left(\min ^{-1}[Q]^{1-\mathrm{n}}\right), E_{a}$ the activation energy in $\mathrm{J} / \mathrm{mol}, R$ is the

218 universal gas constant $(8.314 \mathrm{~J} /(\mathrm{mol} \mathrm{K}))$ and $T$ is the temperature in $\mathrm{K}$.

219 The modified reaction rate law is coupled with the model for heat and mass transfer (section

220 2.4), allowing the prediction of the texture parameters hardness, gumminess and chewiness from

221 the local temperature development with time. The estimated activation energies, pre-exponential

222 factors and reaction orders by Rabeler and Feyissa, (2017, submitted for publication) were used

223 to solve Eq. (19) and (20).

\section{$224 \quad$ 2.6. Model solution}

225 The coupled PDEs of heat and mass transfer (equations described in section 2.4) and the kinetic

226 models (ODEs) that describe the quality changes (hardness, gumminess and chewiness) (section

227 2.5) were implemented and solved using the finite element method (FEM) in the commercial

228 software, COMSOL Multiphysics 5.2a. The model input parameters are shown in Table 1. A

229 rectangular geometry with the dimensions illustrated in Fig. 2b was built in COMSOL and

230 meshed. Mesh sensitivity analysis was conducted, where the mesh size was decreased in a series

231 of simulations until it had no further impact on the model solution (Kumar and Dilber, 2006).

232

233

Table 1: Model input parameters

\begin{tabular}{lllll}
\hline Parameter & Symbol & Value & Unit & Source \\
\hline $\begin{array}{l}\text { Density } \\
\text { chicken meat }\end{array}$ & $\rho_{c m}$ & 1050 & $\mathrm{~kg} / \mathrm{m}^{3}$ & $\begin{array}{l}\text { Calculated from (Choi } \\
\text { and Okos, 1986) }\end{array}$ \\
$\quad \rho_{w}$ & 998 & $\mathrm{~kg} / \mathrm{m}^{3}$ & \\
$\begin{array}{l}\text { Diffusion coefficient } \\
\text { Permeability }\end{array}$ & $D$ & $3 \times 10^{-10}$ & $\mathrm{~m}^{2} / \mathrm{s}$ & (Ngadi et al., 2006) \\
& $\kappa$ & $3 \times 10^{-17}$ & $\mathrm{~m}^{2}$ & (Datta, 2006)
\end{tabular}


Viscosity water

$$
\begin{array}{ll}
\mu_{w} & 0.988 \times 10^{-} \quad \text { Pa s } \\
& 3
\end{array}
$$

\begin{tabular}{|c|c|c|c|c|}
\hline Water & $y_{w 0}$ & 0.76 & $\mathrm{~kg} / \mathrm{kg}$ & Measured \\
\hline Protein & $y_{p 0}$ & 0.22 & $\mathrm{~kg} / \mathrm{kg}$ & $\begin{array}{l}\text { (Barbanti and Pasquini, } \\
\text { 2005) }\end{array}$ \\
\hline Fat & $y_{f 0}$ & 0.01 & $\mathrm{~kg} / \mathrm{kg}$ & $\begin{array}{l}\text { (Barbanti and Pasquini, } \\
\text { 2005) }\end{array}$ \\
\hline Ash & $y_{a 0}$ & 0.01 & $\mathrm{~kg} / \mathrm{kg}$ & $\begin{array}{l}\text { (Barbanti and Pasquini, } \\
\text { 2005) }\end{array}$ \\
\hline
\end{tabular}

Initial composition

Latent heat of

vaporization of water

$H_{\text {evap }} \quad 2.3 \times 10^{6} \quad \mathrm{~J} / \mathrm{kg}$

Initial meat temperature

$\begin{array}{lll}T_{0} & 6 & { }^{\circ} \mathrm{C}\end{array}$

Measured

Initial moisture concentration

$C_{0} \quad 0.76$

$\mathrm{kg} / \mathrm{kg}$

Measured

Water vapor concentration in

Cair

0.05

$\mathrm{kg} / \mathrm{kg}$

Measured ambient air

Heat transfer coefficient

$\begin{array}{lllll}\text { High fan speed } & h_{\text {eff }} & 44 & \mathrm{~W} /\left(\mathrm{m}^{2} \mathrm{~K}\right) & \text { Measured } \\ & h_{\text {bot }} & 59 & \mathrm{~W} /\left(\mathrm{m}^{2} \mathrm{~K}\right) & \\ \text { Low fan speed } & h_{\text {eff }} & 21 & \mathrm{~W} /\left(\mathrm{m}^{2} \mathrm{~K}\right) & \text { Measured } \\ & h_{\text {bot }} & 41 & \mathrm{~W} /\left(\mathrm{m}^{2} \mathrm{~K}\right) & \end{array}$

\section{3. Materials and Methods}

\section{$236 \quad$ 3.1. Sample preparation and oven settings}

237 Chicken breast meat (skinless and boneless) was purchased from a local supermarket the same

238 day as the experiments and stored in plastic bags at $4{ }^{\circ} \mathrm{C}$ until it was used. For all roasting

239 experiments, the chicken breasts were cut into rectangular blocks with the dimensions of $0.04 \mathrm{~m}$

$240 \times 0.02 \mathrm{~m} \times 0.07 \mathrm{~m}$ and a weight of $63 \mathrm{~g} \pm 2 \mathrm{~g}$. The fiber direction for all samples was along the $\mathrm{x}-$

241 axis (see Fig. 2). 
242 A professional convection oven with roasting chamber dimensions of $0.45 \mathrm{~m} \times 0.50 \mathrm{~m} \times 0.65 \mathrm{~m}$

243 was used for the roasting experiments. Dry hot air was circulated inside the roasting chamber by

244 a fan, while the fan speed (air speed) could be adjusted. The oven temperature was controlled by

245 the oven thermostat and additionally two thermocouples were placed at different positions in the

246 oven to measure the oven temperature continuously. The measured oven temperature was stable

247 around the set point with a standard deviation of $\pm 3{ }^{\circ} \mathrm{C}$. Before each experimental run, the oven

248 was preheated to the desired temperature for $30 \mathrm{~min}$ to ensure steady state conditions. The

249 following process settings were used to show the effect of process conditions on the temperature,

250 moisture and texture profile and to validate the developed model:

$251 \quad$ Setting I: $\quad T_{\text {oven }}=170^{\circ} \mathrm{C}$, high fan speed (HF)

$252 \quad$ Setting II: $\quad T_{\text {oven }}=230^{\circ} \mathrm{C}$, high fan speed (HF)

$253 \quad$ Setting III: $\quad T_{\text {oven }}=230^{\circ} \mathrm{C}$, low fan speed (LF)

\section{$254 \quad$ 3.2. Experimental data}

\section{3.2.1. Heat transfer coefficient}

256 The combined heat transfer coefficient, which is the sum of the radiative and convective heat

257 transfer coefficient, was estimated using the lumped method (Sakin et al., 2009). The oven was

258 preheated for 30 min before the experiments to ensure steady state conditions. Polished silver and

259 black painted aluminum blocks (rectangular) were placed in the oven and heated for $20 \mathrm{~min}$ at

$260200{ }^{\circ} \mathrm{C}$. The temperature in the center of the blocks was recorded continuously by using a

261 thermocouple. As the Biot number was smaller than 0.1 the lumped heat transfer method was

262 used and the combined heat transfer coefficient estimated as described by Feyissa et al. (2013).

263 Only minor differences (less than 5\%) between the estimated heat transfer coefficients for the

264 black and polished aluminum block was found. This means that the radiative heat transfer from 
265 the oven walls is small compared to the convective heat transfer. Furthermore, the heat flux by

266 radiation (assuming $\left.T_{\text {oven }}=200{ }^{\circ} \mathrm{C}, \varepsilon_{\text {chicken }}=0.8, T_{\text {surf }}=100{ }^{\circ} \mathrm{C}\right)$ is small $(\approx 2 \%$ of the total flux)

267 compared to the convective heat flux. In the model the estimated effective heat transfer

268 coefficient, which includes the radiative effect, was used as described by Kondjoyan and

269 Portanguen (2008), Sakin-Yilmazer et al. (2012) or Zhang and Datta (2006).

\section{3.2.2. Local temperature}

271 In order to measure the temperature profile inside the chicken meat sample, two thermocouples

272 were placed at the center (point A, Fig. 2b)) and close to surface (point B, Fig. 2b) of the sample.

273 One sample was then placed centrally on the roasting tray and the tray positioned in the middle of

274 the oven. The temperature development was measured as function of time with sample intervals

275 of 5 seconds for 15 min (for setting II, see section 3.1) and $20 \mathrm{~min}$ (for setting I and III).

\section{$276 \quad$ 3.2.3. Moisture content}

277 To compare the predicted and measured moisture content at different time steps, roasting

278 experiments were performed with different times: 1, 3, 5, 7, 10 and 15 min for all process

279 settings. For setting I and III (see section 3.1), an additional sample was taken at $20 \mathrm{~min}$ of

280 roasting. The samples were taken out of the oven after the corresponding roasting time, sealed in

281 plastic bags and placed in ice water to stop further water loss from the surface. The average

282 moisture content of the whole chicken meat sample was then measured using the oven drying

283 method (Bradley, 2010). The samples were minced, weighed in aluminum cups and dried for 24

284 hours at $105^{\circ} \mathrm{C}$. From the weight difference before and after the drying, the moisture content of 285 the chicken meat samples was calculated. 


\subsubsection{Texture measurements}

287 To validate the predicted texture development, roasting experiments were conducted at different 288 time steps: 3, 5, 7, 10, 15 and 20 min (20 min only for Settings I and III, see section 3.1). After

289 the roasting process, the samples were immediately placed in ice water for 4 min to cool them

290 down quickly. The samples were then stored at room temperature for 2 hours in sealed aluminum

291 cups before the texture measurements.

292 To measure the textural changes of chicken breast meat, double compression tests (TPA) were 293 performed according to the procedure described by Rabeler and Feyissa (2017, submitted for

294 publication). A cylindrical probe with a height of $6 \mathrm{~mm} \pm 0.5$ and a diameter of $21 \mathrm{~mm} \pm 1$ was

295 cut out of the middle of the roasted chicken samples using a cork borer. The same sample

296 dimension as in Rabeler and Feyissa (2017, submitted for publication) were used for the TPA

297 measurements. The samples were compressed to a final strain of $40 \%$, setting the test speed to 1

$298 \mathrm{~mm} / \mathrm{s}$ with time interval of 5s between the first and second stroke. The TPA parameters hardness,

299 gumminess and chewiness were then calculated from the recorded force-time plot (Bourne, 300 2002).

\subsection{Statistical analysis}

302 The chi-square test was used to evaluate the goodness-of-fit between the model predictions and

303 the experimental data for the temperature, moisture and texture (Eq. 21) (Taylor, 1997):

$304 \quad \chi^{2}=\sum_{i=1}^{n} \frac{\left(\widehat{\theta}_{i}-\theta_{i}\right)^{2}}{\sigma_{i}{ }^{2}}$

305 with $\hat{\theta}$ the predicted value, $\theta$ the measured value and $\sigma$ the standard deviation. A significance

306 level of $\mathrm{P}<0.05$ was used.

307 Furthermore, the root mean squared error (RMSE) was calculated by using Eq. (22):

$308 \quad R M S E=\sqrt{\frac{\sum_{i=1}^{n}\left(\widehat{\theta}_{i}-\theta_{i}\right)^{2}}{n}}$ 
where $n$ is the total number of samples.

\section{Results and discussion}

\subsection{Temperature and moisture predictions}

312 Fig. 3 presents the predicted core (at position A, Fig. 2b) and surface (at position B. Fig. 2b)

313 temperature as well as the predicted average moisture content as function of the roasting time for

314 the different process settings (Fig.3a for setting I, Fig. 3b for setting II, and Fig. 3c for setting

315 III). A good agreement between the measured (symbols) and predicted (solid lines) temperature

316 profiles at the core $\left(R M S E=1.85,0.83\right.$ and $0.99{ }^{\circ} \mathrm{C}$ for setting I, II and III, respectively) and

317 close to the surface (RMSE $=3.76,2.69$ and $2.6^{\circ} \mathrm{C}$ for setting I, II and III, respectively) was

318 found for all tested process settings. Furthermore, the model showed a high accuracy in the

319 prediction of the average moisture content development of the chicken meat sample with RMSE

320 values of $1.15,1.39$ and $0.91 \%$ for setting I, II and III, respectively $\left(\chi^{2}=4.78,4.66\right.$ and 3.97,

321 respectively, $\mathrm{P}>0.05$ ) (see also Fig. 3a to 3c).
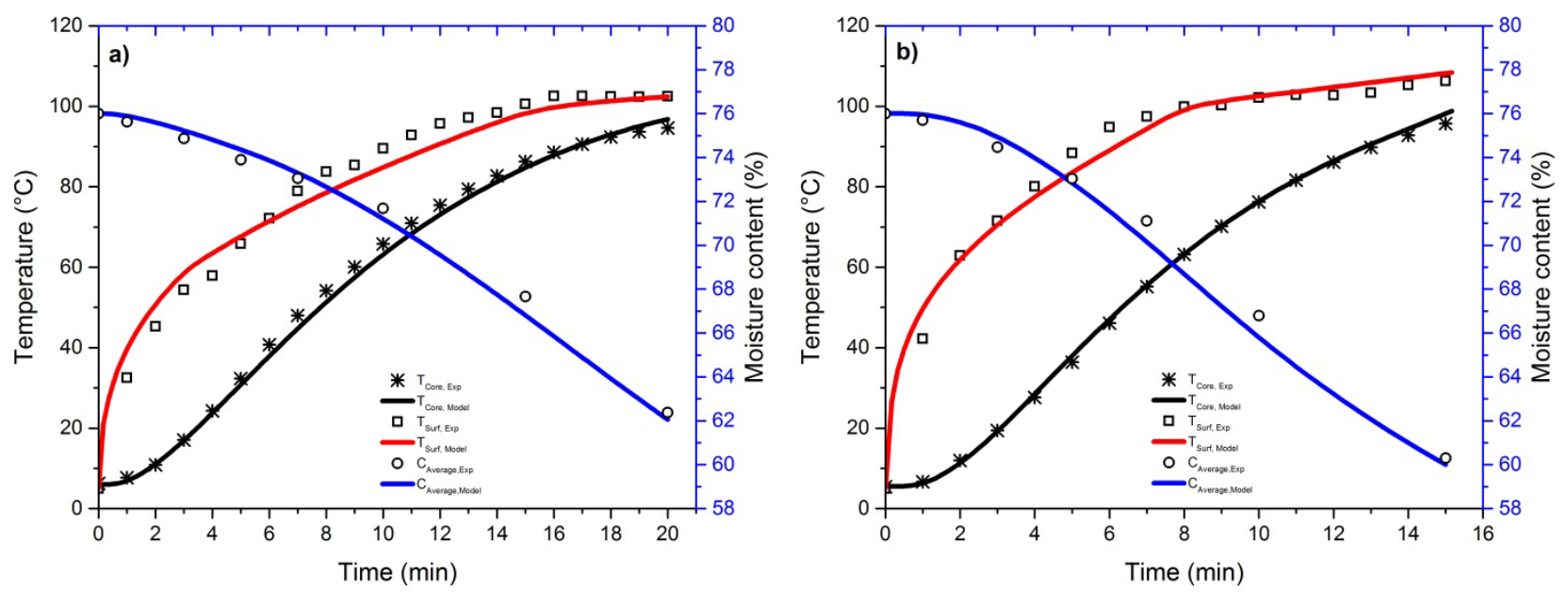


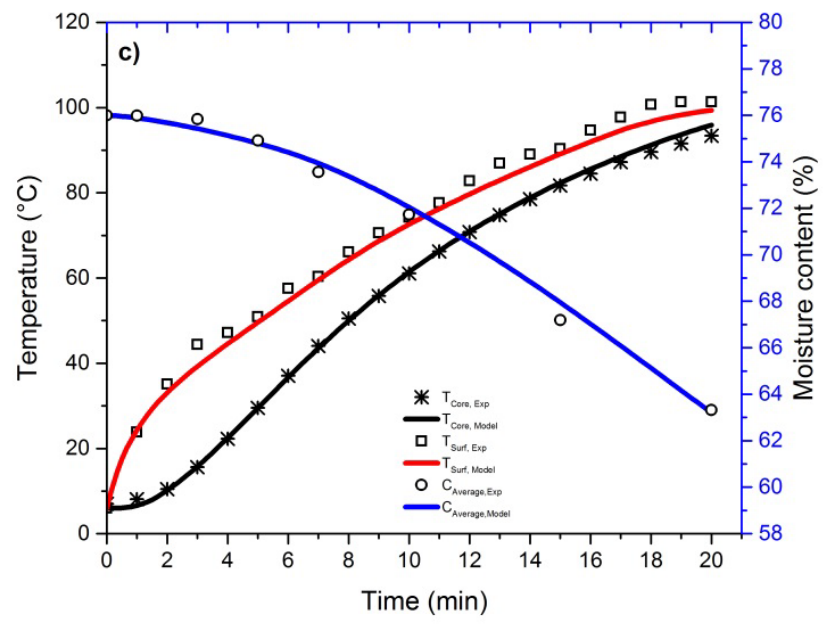

Fig. 3. Comparison between the predicted and measured temperature (core and surface) and moisture development of the chicken meat sample with varying air temperature and fan speed: a) Setting I: Toven $=170{ }^{\circ} \mathrm{C}$, high fan speed; b) Setting II: Toven $=230{ }^{\circ} \mathrm{C}$, high fan speed; c) Setting III: Toven $=230^{\circ} \mathrm{C}$, low fan speed.

324 The process conditions have an influence on the temperature and moisture content profile during 325 the roasting process. Chicken breast meat should be heated to a core (coldest point) temperature 326 of $75{ }^{\circ} \mathrm{C}$ to ensure a safe product for the consumers (Fsis, 2000). The time needed to reach this 327 temperature in the core varies with the process settings: $12.5 \mathrm{~min}, 10 \mathrm{~min}$ and $13 \mathrm{~min}$ roasting 328 time for setting I $\left(T_{\text {oven }}=170{ }^{\circ} \mathrm{C}\right.$ and high fan speed, Fig. 3a), setting II $\left(T_{\text {oven }}=230{ }^{\circ} \mathrm{C}\right.$ and high 329 fan speed, Fig. 3b) and setting III ( $\mathrm{T}_{\text {oven }}=230{ }^{\circ} \mathrm{C}$ and low fan speed, Fig. 3c), respectively.

330 The higher temperature and fan speed for setting II compared to setting I and III, respectively, 331 leads to an increased heat flux from the surrounding hot air to the sample surface. Consequently, 332 the surface temperature is rising faster, which also leads to a faster increase of the core 333 temperature. However, the high surface temperature for setting II results in an increased 334 evaporation of moisture from the chicken meat surface. Therefore, a lower average moisture 335 content is reached for setting II $\left(C_{a v}(t=10 \mathrm{~min}) \approx 66 \%\right.$, Fig. 3b) compared to setting I $\left(C_{a v}(t\right.$ $336=12.5 \mathrm{~min}) \approx 69 \%$, Fig. 3a) and setting III $\left(C_{a v}\left(\mathrm{t}_{75^{\circ} \mathrm{C}}=13 \mathrm{~min}\right) \approx 70 \%\right)$. 
337 Setting I and III show a similar temperature and moisture content development with roasting time

338 (Fig. 3a and 3c, respectively). This is reasonable as the heat flux from the surrounding hot air to

339 the chicken meat surface is comparable for the two settings ( $\dot{q}=3080,5720$ and $2730 \mathrm{~W} / \mathrm{m}^{2}$ for

340 setting I, II and III, respectively) (see Eq. 12 and 13). Thus, the times to reach $75{ }^{\circ} \mathrm{C}$ in the core

341 as well as the moisture contents at this time step are comparable.

\section{4.2. Prediction of texture changes}

343 By coupling the model for heat and mass transfer with the kinetics for textural changes, it is

344 possible to predict the spatial and local texture change inside the chicken meat from the local

345 temperature development. Fig. 4 presents the simulated temperature and texture distributions

346 inside the chicken meat during the roasting in the convection oven (for setting $\mathrm{II}, \mathrm{T}_{\text {oven }}=230{ }^{\circ} \mathrm{C}$

347 and high fan speed) for 5 min (Fig. 4a and 4c) and 10 min (Fig 4b and Fig. 4d).

Temperature distribution $\left({ }^{\circ} \mathrm{C}\right)$
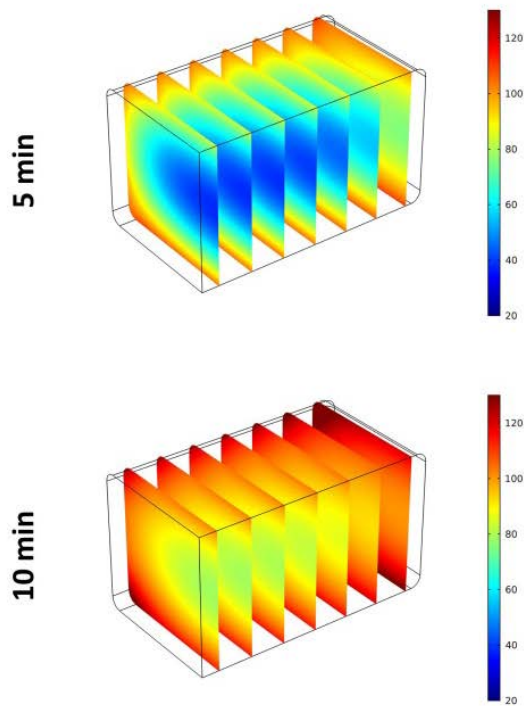

Hardness distribution $(\mathrm{N})$
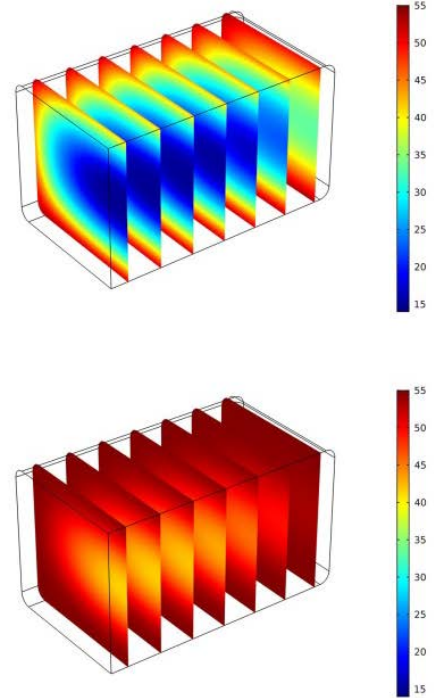

Fig. 4. Visualization of the simulated temperature and hardness distribution during the roasting process: a) temperature profile at $\mathrm{t}=5 \mathrm{~min}$; b) temperature profile at $\mathrm{t}=10 \mathrm{~min}$; $\mathrm{c}$ ) hardness profile at $\mathrm{t}=5 \mathrm{~min}$; d) hardness profile at $\mathrm{t}=10 \mathrm{~min}$. Setting II: Toven $=230^{\circ} \mathrm{C}$, high fan speed. 
350 The results illustrate that the development of the texture parameter hardness, but also the

351 development of the other studied texture parameters (gumminess and chewiness, not shown

352 here), is following the temperature changes. The high heat flux from the surrounding hot air is

353 leading to a fast temperature increase of the chicken meat surface (see also Fig. 3b). This

354 subsequently, results in a fast hardening of the chicken meat at the surface. On the contrary, the

355 internal heat transfer is slow $(\mathrm{Bi}=1.1>0.1)$, which leads to a delayed heat up towards the center

356 of the chicken meat. Accordingly, the hardness at the center is changing slower compared to the

357 surface.

358 Overall, it becomes obvious that the non-uniform temperature development of the chicken meat

359 sample results in the non-uniform texture profiles. The developed model is, therefore, a strong

360 tool to predict the spatial texture development as function of the process conditions and roasting

361 time which is difficult or even not possible to obtain by experimentation alone.

\section{4.3. Effect of process parameters on the texture profile and model validation}

363 In order to study the influence of the oven settings on the texture development of chicken breast

364 meat and to validate the developed model, simulations with two different oven temperatures (230

$365{ }^{\circ} \mathrm{C}$ and $170{ }^{\circ} \mathrm{C}$ ) and fan speeds were compared (see process settings in section 3.1). The

366 predictions of the texture development with roasting time were validated against experimental

367 values that were obtained according to section 3.2.4. Fig. 5a to 5c show that a good agreement

368 between the predicted (solid lines) and experimental measured texture changes (hardness,

369 gumminess and chewiness) (symbols) of chicken breast meat was found for all tested process

370 settings. The RMSE and $\chi^{2}$ values for hardness, gumminess and chewiness are summarized in

371 Table 2. The results further show that the model is able to accurately predict the texture changes

372 of chicken breast meat during roasting for all tested process settings. 

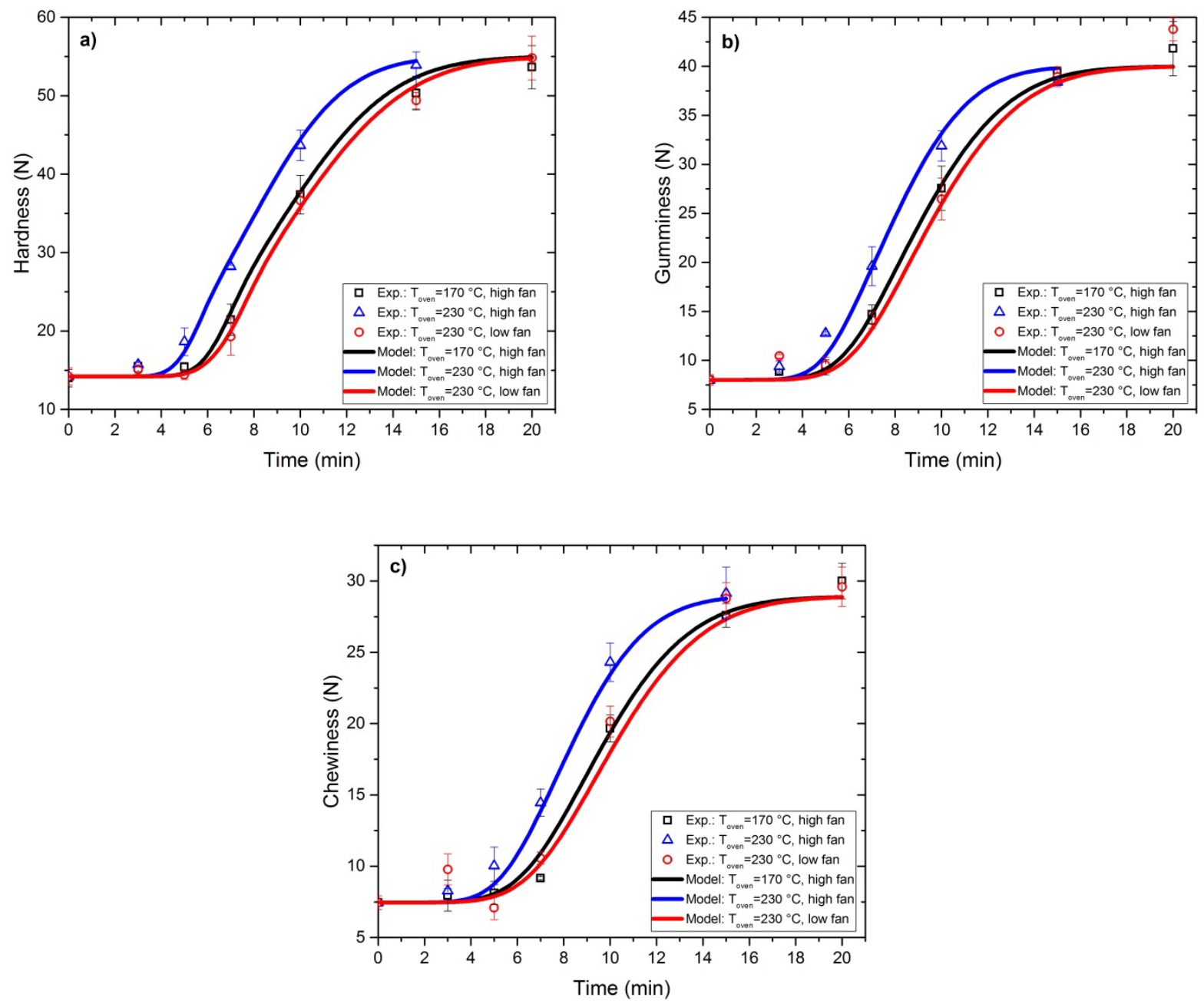

Fig. 5. Effect of process settings on the texture changes of chicken breast meat and comparison between predicted (lines) and experimental values (symbols): a) hardness (N), b) gumminess, c) chewiness. Bars indicate the standard deviation (n = 3).

Table 2: RMSE and $\chi^{2}$ values for hardness, gumminess and chewiness for process setting I, II, and III.

\begin{tabular}{|c|c|c|c|c|c|c|}
\hline & \multicolumn{2}{|c|}{ Hardness } & \multicolumn{2}{|c|}{ Gumminess } & \multicolumn{2}{|c|}{ Chewiness } \\
\hline & RMSE & $x^{2}$ & $R M S E$ & $x^{2}$ & RMSE & $x^{2}$ \\
\hline Setting I & $2.06 \mathrm{~N}$ & 7.12 & $1.79 \mathrm{~N}$ & 2.35 & $2.12 \mathrm{~N}$ & 7.50 \\
\hline Setting II & $1.70 \mathrm{~N}$ & 2.90 & $2.11 \mathrm{~N}$ & 5.12 & $2.11 \mathrm{~N}$ & 3.63 \\
\hline Setting III & $2.25 \mathrm{~N}$ & 6.20 & $2.08 \mathrm{~N}$ & 6.33 & $2.73 \mathrm{~N}$ & 7.17 \\
\hline
\end{tabular}


The oven temperature has a high influence on the texture (hardness, gumminess and chewiness)

378 profiles (Fig. 5a to 5c). A higher value of $T_{\text {oven }}$ leads to an increased heat flux from the

379 surrounding hot air to the chicken meat surface (see Eq. (10) and Eq. (11)) which results in a

380 faster heat up of the sample (see also Fig. 3a and 3b). Therefore, the texture parameters (that are a

381 function of the local temperature development with time) start to rise earlier for the oven

382 temperature of $230{ }^{\circ} \mathrm{C}$ (red line) compared to $170{ }^{\circ} \mathrm{C}$ (black line) (setting II and I, respectively).

383 A higher fan speed results in a higher heat transfer coefficient ( $h_{\text {eff }}$ and $h_{\text {bot, }}$, see Table 1$)$ which

384 leads to an increased heat flux to the chicken meat surface (see Eq. (10) and Eq. (11)).

385 Accordingly, the texture parameter rise earlier for the high fan speed (black lines, Fig. 4)

386 compared to the low fan speed (blue lines).

387 However, only a slight difference in the predicted profiles for hardness, gumminess and

388 chewiness was found between the oven settings I and III (see section 3.1). This is reasonable as a

389 similar temperature development of the two different oven settings was found (compare Fig. 3a

390 with 3c), which results in the similar texture changes.

391 The predicted changes of the storage modulus with heating time for the tested process settings are

392 presented in Fig. 6. A similar trend between the storage modulus and the TPA parameters

393 hardness, gumminess and chewiness development with time was found for all tested process

394 settings (compare Fig. 6 with Fig. 5a - 5c). Setting II (230 ${ }^{\circ} \mathrm{C}$, high fan speed) leads to an earlier

395 rise of the storage modulus compared to the lower oven temperature (setting I) and lower fan

396 speed (setting III). Similar to the TPA parameters development only slight differences in the

397 storage modulus development was observed between setting I and III (see Fig. 6). However, we

398 found that the storage modulus starts to rise later (around $55^{\circ} \mathrm{C}$ ) compared to the texture

399 parameters hardness, gumminess and chewiness (around $45^{\circ} \mathrm{C}$ ) (compare Fig. 6 with Fig. $5 \mathrm{a}-$

400 5c). This earlier increase of the TPA parameters could be due to the earlier decrease of the water 
401 holding capacity at around $40{ }^{\circ} \mathrm{C}$ which leads to a water release into the pore spaces between the

402 meat fibers (Micklander et al., 2002; van der Sman, 2013). Consequently, parts of the

403 compression energy (TPA measurements) could be dissipated as a result of the viscous flow of

404 the fluid in the pore space which results in a toughening of the meat (Tornberg, 2005) . However,

405 deeper analyses of the heat induced changes in the microstructure of chicken breast meat are

406 necessary to obtain a clear relationship between the storage modulus and the TPA parameters

407 hardness, gumminess and chewiness.

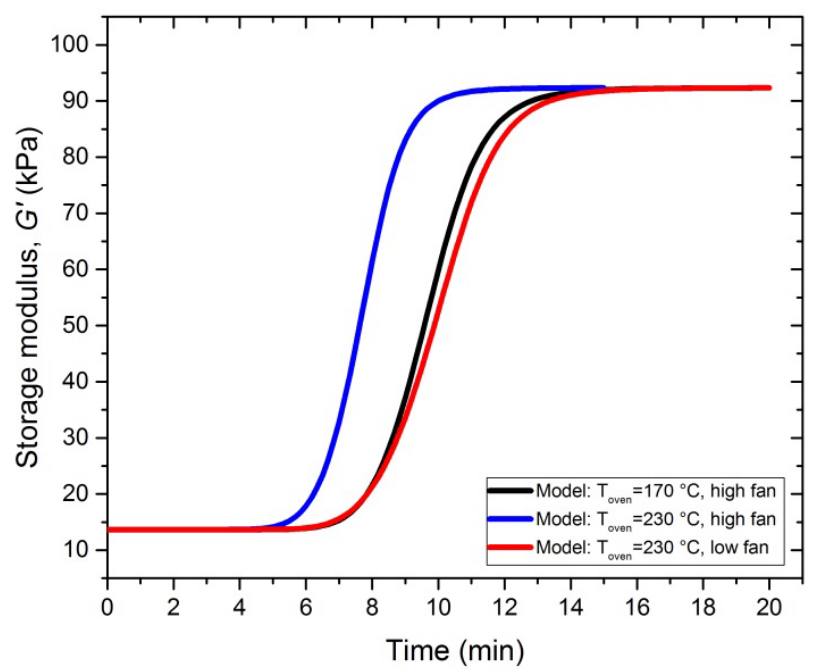

Fig. 6. Predicted storage modulus (G') development with time for the oven settings I (black line), II (blue line) and III (red line).

412 Overall, the results show that by adjusting the oven settings, the texture of the chicken meat

413 sample can be influenced. Consequently, the developed model can be used to control the quality

414 (texture) of the product and to optimize the roasting process to obtain a safe final product with the 415 highest quality for the consumer.

\section{Conclusion}


417 In this study, a mechanistic model of heat and mass transfer was developed for the roasting of

418 chicken breast meat in a convection oven. The developed model was then coupled with the

419 kinetics for heat induced texture changes. This enabled the prediction of the spatial and local

420 texture development as function of the process parameters. The simulation results were validated

421 against experimental obtained values. The developed model provides a more detailed

422 understanding of the process mechanisms during roasting chicken breast meat.

423 We showed that the non-uniform temperature distribution inside the chicken meat sample during

424 the roasting process, leads to a non-uniform texture profile. Furthermore, the clear effect of

425 changing roasting parameters on the texture development was obtained. The developed model

426 enables, thus, a deep insight into the effects of the process conditions on the texture changes of

427 chicken breast meat that is difficult or even not possible to obtain by experimentation alone. 


\begin{tabular}{|c|c|c|c|}
\hline$a_{w}$ & water activity & Greek symbols & \\
\hline$C$ & mass concentration (kg/kg) & $\alpha$ & pre-factor (-) \\
\hline$C_{p}$ & specific heat capacity $(\mathrm{J} /(\mathrm{kg} \mathrm{K}))$ & $\beta$ & $\begin{array}{l}\text { mass transfer coefficient } \\
(\mathrm{m} / \mathrm{s})\end{array}$ \\
\hline$C w$ & chewiness & $\kappa$ & permeability $\left(\mathrm{m}^{2}\right)$ \\
\hline$D$ & diffusion coefficient $\left(\mathrm{m}^{2} / \mathrm{s}\right)$ & $\mu$ & dynamic viscosity (Pa s) \\
\hline$E_{a}$ & activation energy (J/mol) & $\rho$ & density $\left(\mathrm{kg} / \mathrm{m}^{3}\right)$ \\
\hline$G^{\prime}$ & storage modulus $(\mathrm{Pa})$ & $\phi$ & volume fraction \\
\hline Gu & Gumminess & $\hat{\theta}_{i}$ & $\begin{array}{l}\text { predicted value }(T, C, H a \text {, } \\
G u, C w)\end{array}$ \\
\hline$h$ & heat transfer coefficient $\left(\mathrm{W} /\left(\mathrm{m}^{2} \mathrm{~K}\right)\right)$ & $\theta_{i}$ & $\begin{array}{l}\text { measured value ( } T, C, H a \text {, } \\
G u, C w)\end{array}$ \\
\hline $\mathrm{Ha}$ & hardness (N) & $\sigma$ & standard deviation \\
\hline$k$ & reaction rate constant (1/min) & $\chi^{2}$ & chi-square value \\
\hline$k_{0}$ & pre-exponential factor (1/min) & & \\
\hline$k_{i}$ & thermal conductivity $(\mathrm{W} /(\mathrm{m} \mathrm{K}))$ & Subscripts & \\
\hline$M_{w}$ & $\begin{array}{l}\text { molar weight of water }(0.018 \\
\mathrm{kg} / \mathrm{mol})\end{array}$ & & \\
\hline$n$ & number of samples & $a, f, p, w$ & ash, fat, protein, water \\
\hline$p$ & swelling pressure $(\mathrm{Pa})$ & bot & bottom \\
\hline$Q$ & quality attribute & $\mathrm{cm}$ & chicken meat \\
\hline$R$ & $\begin{array}{l}\text { universal gas constant }(8.314 \mathrm{~J} / \mathrm{mol} \\
\mathrm{K})\end{array}$ & eff & effective \\
\hline$T$ & temperature $(\mathrm{K})$ & $\mathrm{eq}$ & equilibrium \\
\hline$t$ & time (s) & ext & external \\
\hline$u$ & velocity (m/s) & surf & surface \\
\hline$y$ & mass fraction & $\begin{array}{l}\text { sat } \\
\text { tot }\end{array}$ & $\begin{array}{l}\text { saturation } \\
\text { total }\end{array}$ \\
\hline TPA & texture profile analyses & 0 & initial $(\mathrm{t}=0)$ \\
\hline $\mathrm{Bi}$ & Biot number & & \\
\hline RMSE & Root-mean-squared-error & & \\
\hline
\end{tabular}




\section{References}

433 Barbanti, D., Pasquini, M., 2005. Influence of cooking conditions on cooking loss and tenderness

434 of raw and marinated chicken breast meat. LWT - Food Sci. Technol. 38, 895-901.

435 doi:10.1016/j.lwt.2004.08.017

436 Barrière, B., Leibler, L., 2003. Kinetics of solvent absorption and permeation through a highly swellable elastomeric network. J. Polym. Sci. Part B Polym. Phys. 41, 166-182. doi:10.1002/polb.10341

Bird, R.B., Stewart, W.E., Lightfoot, E.N., 2007. Transport Phenomena, Revised 2n. ed. John Wiley \& Sons, Inc.

441 Bourne, M.C., 2002. Principles of Objective Texture Measurement. Food Texture Viscosity Concept Meas. 2nd Ed.

Bradley, R.L.J., 2010. Food Analysis, in: Nielsen, S.S. (Ed.), Food Analysi S. Springer-Verlag, West Lafayette, IN, USA, pp. 85-104.

Chang, H.C., Carpenter, J.A., Toledo, R.T., 1998. Modeling Heat Transfer During Oven Roasting of Unstuffed Turkeys. J. Food Sci. 63, 257-261. doi:10.1111/j.1365-2621.1998.tb15721.x

Chen, H., Marks, B.P., Murphy, R.Y., 1999. Modeling coupled heat and mass transfer for

Choi, Y., Okos, M.R., 1986. Effects of temperature and composition on the thermal properties of foods. Food Eng. Process Appl. 93-101.

Christensen, M., Purslow, P.P., Larsen, L.M., 2000. The effect of cooking temperature on mechanical properties of whole meat, single muscle fibres and perimysial connective tissue. Meat Sci. 55, 301-307. doi:10.1016/S0309-1740(99)00157-6 
Feyissa, A.H., Gernaey, K. V., Adler-Nissen, J., 2013. 3D modelling of coupled mass and heat transfer of a convection-oven roasting process. Meat Sci. 93, 810-820. doi:10.1016/j.meatsci.2012.12.003

Fletcher, D.L., Qiao, M., Smith, D.P., 2000. The relationship of raw broiler breast meat color and pH to cooked meat color and pH. Poult. Sci. 79, 784-788. doi:10.1093/ps/79.5.784

Fsis, U., 2000. Chicken from Farm to Table 1-8.

Guerrero-Legarreta, I., Hui, Y.H., 2010. Handbook of Poultry Science and Technology, Volume

Huang, E., Mittal, G.S., 1995. Meatball cooking - modeling and simulation. J. Food Eng. 24, 87100. doi:10.1016/0260-8774(94)P1610-A

Isleroglu, H., Kaymak-Ertekin, F., 2016. Modelling of heat and mass transfer during cooking in steam-assisted hybrid oven. J. Food Eng. doi:10.1016/j.jfoodeng.2016.02.027

Kassama, L.S., Ngadi, M.O., Campus, M., 2014. Pore Development and Moisture Transfer in Chicken Meat during Deep-Fat Frying. Dry. Technol. 3937. doi:10.1081/DRT-200054239

Kondjoyan, A., Oillic, S., Portanguen, S., Gros, J.B., 2013. Combined heat transfer and kinetic models to predict cooking loss during heat treatment of beef meat. Meat Sci. 95, 336-344.

Kondjoyan, A., Portanguen, S., 2008. Prediction of surface and “under surface” temperatures on poultry muscles and poultry skins subjected to jets of superheated steam. Food Res. Int. 41, 16-30. doi:10.1016/j.foodres.2007.07.006 in: Sablani, S., Datta, A., Shafiur Rehman, M., Mujumdar, A. (Eds.), Handbook of Food and Bioprocess Modeling Techniques, Food Science and Technology. CRC Press. 
481 Lawrie, R.A., Ledward, D.A., 2006. Lawrie’s meat science.

482 Lewis, G.J., Purslow, P.P., 1989. The strength and stiffness of perimysial connective tissue

483 isolated from cooked beef muscle. Meat Sci. 26, 255-269. doi:10.1016/03091740(89)90011-9

Micklander, E., Peshlov, B., Purslow, P.P., Engelsen, S.B., 2002. NMR-cooking: Monitoring the changes in meat during cooking by low-field 1H-NMR. Trends Food Sci. Technol. 13, 341346. doi:10.1016/S0924-2244(02)00163-2

Ngadi, M., Dirani, K., Oluka, S., 2006. Mass Transfer Characteristics of Chicken Nuggets. Int. J. Food Eng. 2. doi:10.2202/1556-3758.1071

Obuz, E., Powell, T.H., Dikeman, M.E., 2002. Simulation of Cooking Cylindrical Beef Roasts. LWT - Food Sci. Technol. 35, 637-644. doi:10.1006/fstl.2002.0940

Rabeler, F., Feyissa, A.H., 2017. Kinetic modelling of texture and color changes during thermal treatment of chicken breast meat, (manuscript submitted for publication).

494 Sakin-Yilmazer, M., Kaymak-Ertekin, F., Ilicali, C., 2012. Modeling of simultaneous heat and mass transfer during convective oven ring cake baking. J. Food Eng. 111, 289-298.

Sakin, M., Kaymak-Ertekin, F., Ilicali, C., 2009. Convection and radiation combined surface heat transfer coefficient in baking ovens. J. Food Eng. 94, 344-349. doi:10.1016/j.jfoodeng.2009.03.027

500 Taylor, J.R., 1997. An introduction to error analysis: the study of uncertainties in physical 501 measurements, 2nd edition. University Science Books.

502 Thussu, S., Datta, A.K., 2012. Texture prediction during deep frying: A mechanistic approach. J. 503 Food Eng. 108, 111-121. doi:10.1016/j.jfoodeng.2011.07.017 
504 Tornberg, E., 2005. Effects of heat on meat proteins - Implications on structure and quality of 505 meat products. Meat Sci. 70, 493-508. doi:10.1016/j.meatsci.2004.11.021

506 van der Sman, R.G.M., 2013. Modeling cooking of chicken meat in industrial tunnel ovens with 507 the Flory-Rehner theory. Meat Sci. 95, 940-957. doi:10.1016/j.meatsci.2013.03.027

508 van der Sman, R.G.M., 2007. Moisture transport during cooking of meat: An analysis based on 509 Flory-Rehner theory. Meat Sci. 76, 730-738. doi:10.1016/j.meatsci.2007.02.014

510 Wattanachant, S., Benjakul, S., Ledward, D.A., 2005. Effect of heat treatment on changes in 511 texture, structure and properties of Thai indigenous chicken muscle. Food Chem. 93, 337$512 \quad$ 348. doi:10.1016/j.foodchem.2004.09.032

513 Zell, M., Lyng, J.G., Cronin, D.A., Morgan, D.J., 2010. Ohmic cooking of whole turkey meat 514 Effect of rapid ohmic heating on selected product parameters. Food Chem. 120, 724-729. 515 doi:10.1016/j.foodchem.2009.10.069

516 Zhang, J., Datta, A.K., 2006. Mathematical modeling of bread baking process. J. Food Eng. 75, 517 78-89. doi:10.1016/j.jfoodeng.2005.03.058 